\title{
Bridging the Gap between Research and Clinical Practice in Asymptomatic Alzheimer's Disease
}

\author{
A.M. Downing ${ }^{1}$, R. Yaari ${ }^{1}$, D.E. Ball ${ }^{1}$, K.J. Selzler ${ }^{1}$, M.D. Devous, Sr ${ }^{2}$ \\ 1. Lilly Research Laboratories, Lilly Corporate Center, Indianapolis, IN, USA; 2. Avid Radiopharmaceuticals, Inc., a wholly owned subsidiary of Eli Lilly and Company,
} Philadelphia, PA, USA

Corresponding Author: AnnCatherine Downing, Eli Lilly and Company, Lilly Corporate Center, Indianapolis, IN 46285, Email: downing_anncatherine_m@lilly.com, +1 (317) 276-0871

J Prev Alz Dis 2016;3(1):30-42

Published online December 8, 2015, http:/ / dx.doi.org/10.14283/jpad.2015.86

\begin{abstract}
Due to the growing global health impact of Alzheimer's disease $(\mathrm{AD})$, there is a greater need for interventions that prevent or delay the onset of clinical symptoms of this debilitating disease. Clinical trials for disease-modifying compounds in $\mathrm{AD}$ have shifted towards earlier stages in the spectrum of illness, including the stage prior to cognitive symptoms. A population of specific interest for clinical research includes individuals with evidence of Alzheimer's disease pathology who are asymptomatic (ADPa). The challenges and barriers regarding medical treatment of ADPa must be identified and addressed prior to the completion of a positive clinical trial in order to accelerate the translation of research findings to clinical practice. This report applies an existing public health impact model from Spencer and colleagues (2013) to evaluate the readiness of the clinical practice environment to treat $\mathrm{ADPa}$ individuals if a disease-modifying agent achieves approval. We contrast the current clinical practice environment with a potential future state through investigating the effectiveness, reach, feasibility, sustainability, and transferability of the practice of treating ADPa individuals.
\end{abstract}

Key words: Global health impact, environmental evolution, asymptomatic $A D$, prevention.

\section{Introduction}

A lzheimer's disease (AD) has long been conceptualized as a dementia consisting of a progressively worsening cognitive decline leading to the inability to perform daily activities in later stages of the illness. More recently, however, the disease has come to be accepted as a continuum beginning with an asymptomatic phase in the presence of pathological biomarkers. Confronted by a lack of positive $\mathrm{AD}$ treatment trials, but encouraged by results from two AD clinical trials of anti-amyloid therapies suggesting possible drug effect only in earlier symptomatic stages of disease $(1,2)$. Some researchers are shifting efforts to these earlier stages, including the asymptomatic phase. This shift is evidenced by several clinical trials using varied criteria to select individuals within the asymptomatic population (Table 1).

Two predominant independent definitions and guidelines for the diagnosis of asymptomatic $\mathrm{AD}$, the International Working Group (IWG) (3), IWG-2 (4) and the joint effort of the National Institute of Aging and the Alzheimer's Association (NIA-AA) (5), have been published (Figure 1). Both depend on evidence of cerebral AD pathology, but a key difference between these two guidelines is that asymptomatic individuals with biomarker evidence of AD pathology are considered to be at risk for AD by the IWG, while NIA-AA supports a diagnosis of Preclinical AD. Despite this difference, the individuals in the earliest stages of the spectrum are identified by presence of amyloid deposition in the absence of cognitive symptoms (6), which is estimated to be present in approximately $20-30 \%$ of cognitively healthy individuals aged 65-90 years (7).

Figure 1. Alzheimer's disease depicted as a continuum/ spectrum incorporating the NIA-AA and IWG criteria (Dubois et al., 2010; Dubois et al., 2007; Sperling et al., 2011). Although the terminology differs in the earliest stage, both include evidence of elevated brain amyloid without the presence of clinical symptoms, specifically cognitive decline

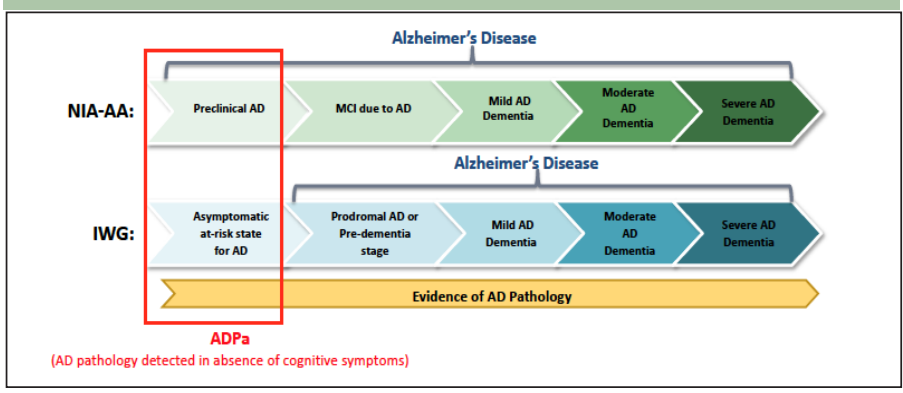

Abbreviations: ADPa, Alzheimer's disease pathology, asymptomatic; IWG, International Working Group; MCI, mild cognitive impairment; NIA-AA, National Institute of Aging and the Alzheimer's Association

Should an effective therapy in asymptomatic AD be realized, several barriers to its use in clinical practice will need to be overcome. First, agreement will need to be reached on the concept that a pathologic biomarker alone is sufficient to make a diagnosis. Until this alignment is achieved, for the purposes of this paper, we refer to 
Table 1. Description of Populations in Current Asymptomatic AD Clinical Trials

\begin{tabular}{|c|c|c|c|c|c|c|}
\hline Study & Age & Sample Size & $\begin{array}{l}\text { Biomarker/Risk } \\
\text { factor }\end{array}$ & $\begin{array}{l}\text { Cognitive } \\
\text { Inclusion Criteria }\end{array}$ & Intervention & Duration \\
\hline $\begin{array}{l}\text { Alzheimer's Pre- } \\
\text { vention Initiative } \\
\text { (API) PSEN1 } \\
\text { E280A Autoso- } \\
\text { mal Dominant } \\
\text { Study* },+\end{array}$ & $30-60$ & $\sim 300^{*}$ & $\begin{array}{l}\text { Carriers of } \\
\text { the autosomal } \\
\text { dominant } \\
\text { presenilin-1 } \\
\text { E280A mutation } \\
\text { in Antioquia, } \\
\text { Colombia }\end{array}$ & $\begin{array}{l}\text { Presymptomatic } \\
\text { (carriers of a } \\
\text { known autosomal } \\
\text { dominant } \\
\text { Alzheimer's } \\
\text { disease mutation } \\
\text { gene who are } \\
\text { asymptomatic) }\end{array}$ & $\begin{array}{l}\text { Subjects are } \\
\text { randomized to } \\
\text { subcutaneous } \\
\text { crenezumab, an } \\
\text { anti-amyloid } \\
\text { monoclonal } \\
\text { antibody, or } \\
\text { placebo }\end{array}$ & 5 years \\
\hline $\begin{array}{l}\text { API Apolipo- } \\
\text { protein E (APOE) } \\
\varepsilon 4 \text { Homozygotes } \\
\text { Study } ¥, \S\end{array}$ & $60-75$ & $\sim 1300$ & $\begin{array}{l}\text { Homozygous for } \\
\text { apolipoprotein E } \\
\varepsilon 4 \text { (APOE4) }\end{array}$ & $\begin{array}{l}\text { Cognitively } \\
\text { normal }\end{array}$ & $\begin{array}{l}\text { Subjects to be } \\
\text { randomized } \\
\text { to CAD-106, } \\
\text { an active } \\
\text { anti-amyloid } \\
\text { immunotherapy, } \\
\text { a BACE inhibitor, } \\
\text { or placebo }\end{array}$ & 5 years \\
\hline $\begin{array}{l}\text { Dominantly } \\
\text { Inherited } \\
\text { Alzheimer's } \\
\text { Network Trials } \\
\text { Unit (DIAN- } \\
\text { TU)। I,\{ }\end{array}$ & $\begin{array}{l}\text { 18-80, dependent } \\
\text { upon expected } \\
\text { age of onset }\end{array}$ & $\sim 210^{*}$ & $\begin{array}{l}\text { Autosomal } \\
\text { dominant } \\
\text { mutations in one } \\
\text { of three genes } \\
\text { (APP, PSEN1, or } \\
\text { PSEN2) }\end{array}$ & $\begin{array}{l}\text { Majority of } \\
\text { subjects are } \\
\text { presymptomatic, } \\
\text { but also includes } \\
\text { Mild Cognitive } \\
\text { Impairment } \\
\text { and mild AD } \\
\text { dementia }\end{array}$ & $\begin{array}{l}\text { Subjects are } \\
\text { randomized } \\
\text { to one of two } \\
\text { anti-amyloid } \\
\text { monoclonal } \\
\text { antibodies } \\
\text { (gantenerumab } \\
\text { and } \\
\text { solanezumab) or } \\
\text { placebo }\end{array}$ & $\begin{array}{l}4 \text { years with } \\
\text { 2-year biomarker } \\
\text { interim analysis }\end{array}$ \\
\hline 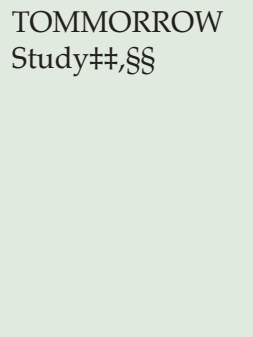 & $65-83$ & $\sim 5800$ & $\begin{array}{l}\text { Inclusion based } \\
\text { on an algorithm } \\
\text { using age and } \\
\text { variants of the } \\
\text { APOE and } \\
\text { TOMM40 genes } \\
\text { for predicting AD } \\
\text { risk }\end{array}$ & $\begin{array}{l}\text { Cognitively } \\
\text { normal }\end{array}$ & $\begin{array}{l}\text { Subjects are } \\
\text { randomized to } \\
\text { pioglitazone, } \\
\text { a agonist for } \\
\text { peroxisome } \\
\text { proliferator- } \\
\text { activated } \\
\text { receptor- } \gamma \text {, or } \\
\text { placebo }\end{array}$ & 5 years \\
\hline A5 Study | | | I, \{1 & 60-TBD & TBD & $\begin{array}{l}\text { Evidence of } \\
\text { cerebral amyloid } \\
\text { deposition } \\
\text { accumulation }\end{array}$ & $\begin{array}{l}\text { Cognitively } \\
\text { normal }\end{array}$ & $\begin{array}{l}\text { Subjects to be } \\
\text { randomized to a } \\
\text { BACE inhibitor } \\
\text { (JNJ-54861911) or } \\
\text { placebo }\end{array}$ & TBD \\
\hline
\end{tabular}

${ }^{*}$ These values reflect planned enrollment, however, they also include mutation negative participants; *Reiman et al., JAD 2011; +Rodriguez-Gomez et al., JAD 2014; $\neq$ Reiman et al., in press; Shttp:/ / www.alzforum.org/news/ conference-coverage/novartis-partner-banner-health-apoe4-prevention-trial; Accessed 8 June 2015; I I Morris et al., Clinical investigation. 2012; \{https:/ / www.clinicaltrials.gov/ct2/ show/NCT01760005; \#Donohue et al., JAMA Neurology 2014; ;*https: / clinicaltrials.gov/ ct2/ show / NCT02008357; +†Sperling et al., Science translational medicine. 2014; ‡キRoses et al., Alzheimers Dement 2014; §§https:/ clinicaltrials.gov/ct2/show/NCT01931566; I I I I Sperling et al., Neuron. 2014; \{ \{http: / / www.alzforum.org/news/ community-news/davies-sperling-share-2015-potamkin-prize; Accessed 8 July 2015 
the population commonly defined by both the NIAAA and IWG criteria as Alzheimer's disease pathology, asymptomatic (ADPa). The term ADPa intentionally does not specify which biomarker (or combination of biomarkers) is required to identify such subjects, as the field of in vivo AD biomarkers is rapidly evolving. Second, a therapeutic agent will need to show efficacy in preventing decline or delaying symptom onset and possess an acceptable risk profile. Since alignment on ways to demonstrate clinical meaningfulness in this population has not yet been achieved, approval and reimbursement of therapy for this condition will be challenging. Third, the clinical practice environment will need to evolve to include diagnosis and treatment of ADPa individuals in addition to diagnosis and treatment of symptomatic stages of AD. In this new paradigm, emerging challenges will include how to identify persons with ADPa, and who among those to treat. These hurdles must be overcome in order for a treatment to be accessible to individuals who may benefit. Although prevention of $\mathrm{AD}$ due to lifestyle and vascular related risk factors as well as diagnostic and ethical challenges in this population have previously been highlighted (8-10), this paper uses a public health viewpoint to further evaluate changes required to pave the way to reaching those who may benefit from a treatment for asymptomatic $\mathrm{AD}$.

A number approaches to understanding the barriers to treating an ADPa preclinical population could be pursued. We employed an existing conceptual public health framework, as outlined by Spencer and colleagues (11), to consider the current environment of AD diagnosis and treatment as well as a future state with an approved AD disease-modifying therapy (Table 2). One advantage of this framework is that it allows environmental factors to be evaluated separately from therapy. The five specific impact elements of this model are described in the following sections and include effectiveness, reach, feasibility, sustainability, and transferability. Specifically "the practice" under evaluation is the paradigm shift towards treatment of individuals who have AD pathology, but are cognitively asymptomatic (ADPa), with a disease-modifying therapy.

\section{Effectiveness}

\section{What beneficial outcomes could be achieved through the successful treatment of asymptomatic AD individuals with a disease-modifying therapy?}

Support for the approach of treating ADPa individuals with a disease-modifying therapy comes from the precedent of early intervention in other disease states, limitations of current treatments, and recent evidence suggesting that interventions earlier in the $\mathrm{AD}$ continuum may result in better social and economic outcomes. The substantially increasing size of the elderly population over the next several decades and the burden that AD will cause, has led multiple countries to develop national plans to address AD to help achieve this global aim (12). These include the US National Plan to Address Alzheimer's Disease that states a goal of preventing and effectively treating AD by 2025 (13). Further, the G8 stated at the 2013 Dementia Summit Declaration that their ambition was to "identify a cure or a diseasemodifying therapy for dementia by 2025" (14).

Many reports have highlighted the economic impact and burden upon health care systems that Alzheimer's disease has and will continue to have over the coming years if there is no paradigm shift in treatment approaches (15-18). The Alzheimer's Association Report (2015) currently estimates that 5.1 million Americans are diagnosed with $\mathrm{AD}$ and with the growing population, is expected to reach 13.5 million by 2050 (16). In 2015, the total cost of healthcare for Americans over 65 years with $\mathrm{AD}$ or other dementia was $\$ 226$ billion and is projected to increase to over $\$ 1.1$ trillion by 2050 (16). Another report estimated the worldwide costs of dementia in 2010 to be $\$ 604$ billion, with the majority of costs occurring in North America and Western Europe (17). According to the World Health Organization, dementia is one of the major causes of disability in older people with 47.5 million people currently diagnosed with dementia and 7.7 million new cases every year (19). The total number is projected to nearly triple by 2050 with an estimated 135.5 million people worldwide diagnosed with dementia (19). Health and social care systems across the globe are not prepared to absorb this increased demand. Much of the cost burden of $\mathrm{AD}$ is driven by the late stages of the disease (i.e. dementia), so avoiding or reducing the time spent in later stages of the disease would correspondingly reduce the overall burden of disease.

A recent study estimated that if a disease-modifying treatment were available to delay the onset of Alzheimer's by five years, it would result in savings of $\$ 935$ billion in the first 10 years in the United States alone (16). While this report suggested that there will be a significant overall savings to the health care system if Alzheimer's can be slowed or prevented, the potential therapy-related costs were not considered. However, a disease-modifying therapy for ADPa individuals that successfully delays or prevents the onset of dementia would provide benefit in a number of different ways. The potential exists for a decrease in incident dementia. ADPa individuals would be able to interact and function independently for a longer time period. Family members and other individuals would benefit from avoiding or delaying the need to provide assistance as $\mathrm{AD}$ progressed. Other conceivable benefits may be realized as well, but as a recent study noted, medical advances delaying the onset of $\mathrm{AD}$ have the potential to help maintain the well-being of individuals and have a significant economic impact (20).

The formation of groups such as the Global Dementia 


\begin{tabular}{|c|c|c|}
\hline Element & Definition of Element & Sample of Questions \\
\hline \multirow[t]{5}{*}{ Effectiveness } & $\begin{array}{l}\text { Extent of which the practice achieves the desired } \\
\text { outcomes }\end{array}$ & -What are the practice's desired outcomes? \\
\hline & & - How consistent is the evidence? \\
\hline & & $\begin{array}{l}\text { - What is the magnitude of the effect, including efficiency } \\
\text { or effectiveness or both, as appropriate? }\end{array}$ \\
\hline & & $\begin{array}{l}\text { - What is the significance to the public health, systems, } \\
\text { or organizational outcomes }\end{array}$ \\
\hline & & $\begin{array}{l}\text { - To what extent does the practice achieve the desired } \\
\text { outcomes? }\end{array}$ \\
\hline \multirow[t]{5}{*}{ Reach } & $\begin{array}{l}\text { Extent that the practice affects the intended and } \\
\text { critical target population(s) }\end{array}$ & $\begin{array}{l}\text { - What is the practice's intended and critical target } \\
\text { population (individuals, customers, staff, agency, and } \\
\text { other target populations)? }\end{array}$ \\
\hline & & $\begin{array}{l}\text { - What is the proportion of the eligible population } \\
\text { affected by the practice? }\end{array}$ \\
\hline & & $\begin{array}{l}\text { - How much of the population could ultimately be } \\
\text { affected (potential reach)? }\end{array}$ \\
\hline & & $\begin{array}{l}\text { - In considering representatives, does the practice } \\
\text { promote health equity? }\end{array}$ \\
\hline & & $\begin{array}{l}\text { - To what extent does the practice affect the intended } \\
\text { and critical target population(s)? }\end{array}$ \\
\hline \multirow[t]{3}{*}{ Feasibility } & Extent to which the practice can be implemented & -What are the barriers to implementing this practice? \\
\hline & & - What are the facilitators to implementing this practice? \\
\hline & & $\begin{array}{l}\text { - What resources are necessary to fully implement the } \\
\text { practice? }\end{array}$ \\
\hline \multirow[t]{3}{*}{ Sustainability } & $\begin{array}{l}\text { Extent to which the practice can be maintained } \\
\text { and achieve desired outcomes over time }\end{array}$ & $\begin{array}{l}\text { - How is the practice designed to integrate with existing } \\
\text { programs or processes or both? }\end{array}$ \\
\hline & & $\begin{array}{l}\text { - What level of resources is required to sustain the } \\
\text { practice over time? }\end{array}$ \\
\hline & & $\begin{array}{l}\text { - How has the practice been maintained to achieve its } \\
\text { desired outcomes over time? }\end{array}$ \\
\hline \multirow[t]{4}{*}{ Transferability } & $\begin{array}{l}\text { Extent to which the practice can be applied to or } \\
\text { adapted for various contexts }\end{array}$ & - How has the practice been adapted? \\
\hline & & $\begin{array}{l}\text { - What is the impact of varying political, organizational, } \\
\text { geographic, social, and economic climates? }\end{array}$ \\
\hline & & $\begin{array}{l}\text { - How has the practice been proven to be effective in } \\
\text { different settings? }\end{array}$ \\
\hline & & $\begin{array}{l}\text { - To what extent has the practice been applied to or } \\
\text { adapted for a variety of contexts? }\end{array}$ \\
\hline
\end{tabular}

Discovery Fund, Innovative Medicines InitiativeEuropean Prevention of Alzheimer's Dementia Consortium (IMI-EPAD), the Global CEO Initiative Global Alzheimer's Platform (CEOi-GAP) and the Collaboration for Alzheimer's Prevention (CAP) are meant to align research efforts and foster collaboration to "defeat this devastating disease" (21). AD researchers are focusing their efforts toward drugs targeting disease pathology modification early in the AD spectrum; however, the data to support this approach are currently limited. Numerous research studies in symptomatic stages of AD have failed to show significant benefit on primary outcome measures (22), but two post-hoc analyses from these large research programs suggest a potential for targeting earlier stages of the AD continuum. Solanezumab, a humanized anti-amyloid monoclonal antibody, did not meet primary endpoints in two, 18-month Phase 3 studies in patients with mild or moderate $\mathrm{AD}$ dementia (1). However, a pooled posthoc analysis of the two studies showed a significant slowing of cognitive and functional decline in the mild dementia group (23). A Phase 2 study of crenezumab, 
another anti-amyloid monoclonal antibody, also did not meet primary endpoints, but an exploratory analysis demonstrated a significant reduction in cognitive decline in the mild dementia group (2). While these results offer encouragement, confirmatory data from Phase 3 trials in the mild dementia population are required. Additionally, clinical trial data in the ADPa population are required to establish whether earlier treatment increases efficacy of disease-modifying agents.

Health care systems are also likely to request outcome data to quantify the impact of disease-modifying therapy. The duration of current asymptomatic clinical trials, of approximately 3 years to 5 years in length, were powered for biomarker or cognitive endpoints and may not generate longer-term outcome data. For example, a longer-term measure of interest may be assessing whether independent functioning of activities of daily life are preserved or maintained when treating ADPa. To address this gap, statistical modeling of clinical trial data could be used to estimate the potential longer-term impact. Alternatively, surrogate or proxy endpoints may be established to show the value of ADPa treatment prior to symptom onset (24). Observational studies could also be helpful to assess the impact of newly introduced disease-modifying treatment(s) in a real-world setting over sufficient duration.

\section{Reach}

Once an ADPa treatment is available that achieves an appropriate effectiveness threshold, how will clinicians "reach" the asymptomatic AD patients in clinical practice?

Research has shown that symptomatic AD is underdiagnosed with diagnosis of only $20-50 \%$ of cases in developed countries and even a smaller percentage in less developed countries (25). Alzheimer's Disease International suggests "approximately 28 million of the 36 million people with dementia have not received a diagnosis, and therefore do not have access to treatment, care and organized support that getting a formal diagnosis can provide" (26). When a diagnosis is made, the current clinical management of AD largely engages patients in the later clinical stages of disease, with the majority of patients and caregivers not seeking and/ or receiving care until moderate or severe dementia has ensued. The current clinical paradigm does not support or emphasize the need for early detection, diagnosis, or intervention. To compound the issue, many physicians are currently reluctant to provide a diagnosis because they perceive $\mathrm{AD}$ as an incurable disease without adequate treatment (26).

Today, the diagnosis of symptomatic AD relies on clinical history, examination, and supportive cognitive testing with blood tests and structural imaging to ruleout other etiologies of cognitive symptoms. Because objective biomarker evidence of specific AD pathology is generally obtained in only a minority of cases, misdiagnosis can occur, as evidenced by clinical trial experience. Previous bapineuzumab and solanezumab trials in symptomatic AD enrolled patients based on clinical diagnosis without AD biomarker evidence. Once in the study, amyloid PET imaging was performed on a subset of subjects revealing that as many as $30 \%$ of enrolled subjects may have a non-AD diagnoses based on their pathology (27). As a result, biomarkers are increasingly used as an adjunct to the clinical diagnosis for entry into studies across the AD spectrum and will likely be utilized more frequently in clinical practice, especially once a disease-modifying treatment for $\mathrm{AD}$ is available. Use of biomarkers in the ADPa population may also be helpful to reduce significant and potentially avoidable medical resource use and related costs that have been noted in symptomatic AD (28).

The pros and cons of some diagnostic tests that may measure AD pathology for potential use in clinical practice are summarized in Table 3. Although some of these tools are approved for use in individuals with cognitive symptoms at this time, none of these tests have sufficient data to determine predictive utility for identification of ADPa and do not have regulatory approval for use in clinical practice in the ADPa population. Further, the weight of evidence varies across tools and some have limited levels of evidence. Additionally, risk factors (e.g. age and head-trauma) and co-morbid disorders (e.g. late-onset depression, diabetes, and hypertension) could provide supplemental data on predicting cognitive decline.

Regardless of the specific characteristics used to define the ADPa, the appropriateness of paying for screening remains controversial. The United States Preventative Services Task Force (USPSTF) makes evidencebased recommendations about clinical preventive services. Clinical preventive services that receive recommendations of levels of A or B by the USPSTF will be reimbursed with no cost sharing by new group and individual insurance plans after October 2010 and by Medicare. Currently, the USPSTF finds that there is insufficient evidence to determine whether general population screening for cognitive impairments is more beneficial than harmful (29). However, the Affordable Care Act in the US currently covers annual "wellness" visits that include cognitive screening, though the method for this screening is not currently specified. Information from these wellness visits and other data sources are needed to build an evidence base for cognitive screening practices. When a new treatment that improves outcomes becomes available, it can also impact USPSTF recommendations on screening. The USPSTF recently provided a $B$ level recommendation for Hepatitis B screening in high-risk populations after previously recommending against screening in the general population (30). The rationale for the change 
Table 3. Diagnostic tools for selection of an ADPa population evaluated for potential use in clinical practice

\section{Categories/Examples \\ Imaging Biomarkers \\ Regional Metabolic Cerebral Blood Flow Biomarkers}

\section{F-FDG-PET}

(Bohnen et al., J Nucl Med 2012; Cohen and Klunk, Neurobiol Dis 2014;

Zhang et al., IJCP 2012)

Single-photon emission computed tomography (SPECT)

(Tu et al., Expert Opin Ther Pat 2015)

Regional cerebral blood flow (RCBF) derived from early time points of Amyloid Tracers (PIB and FBP)

(Gietl et al., Neurobiol Aging 2015)

Amyloid PET (4 different tracers available)

- Florbetaben

- Florbetapir

- Flutemetamol

- Pittsburg compound B (PiB)

(noncommercial)

(Rowe and Villemagne, J. Nucl Med 2013)

Tau-PET

(Villemange et al.,The Lancet. Neurol 2015; Chien et al., J Alzheimers Dis 2013; Braak and Braak, Acta Neuropathol 1991)

MRI, volumetric

- Whole brain atrophy

- Hippocampal volume

- Medial temporal lobe atrophy

- Cortical thickness

- Rate of atrophy

(Jack, Neurobiol of Aging 2011)

MRI, Functional (resting state functional connectivity)

(Sperling, Neurobiol of Aging 2011; Gordon et al., Neurobiol of Aging 2015) -relatively high sensitivity/specificity for differentiating AD from healthy controls -useful for distinguishing between AD and FTD in symptomatic individuals -likely that FDG changes precede cerebral volume loss

-widely available

-specificity higher than FDG-PET

-can be completed with amyloid scan with little additional time and cost -analogous to FDG-PET

-high specificity for cerebral brain amyloid

-negative scan can rule out AD -amyloid detectable $10+$ years prior to symptomatic stages of $\mathrm{AD}$ -potential centiloid standardization between tracers

-Tau detectable $\sim 5$ years prior to symptomatic stages of $\mathrm{AD}$

-potential surrogate for disease staging -correlation with known pathological spread

-Region of Interest relationship with clinical symptomatology or clinical presentation

-no radiation exposure

-widely available

-cerebral atrophy has a strong correlation with cognitive decline

-widely available

-cerebral atrophy has a strong correlation with cognitive decline

-commercially available, FDA-approved analysis software available

-no radiation exposure -widely available

-no additional equipment required (in contrast to task-evoked fMRI)

-can be obtained at the same time as a structural scan (little or no extra cost)
Current State - Cons

-cost

-computerized quantitative analysis can improve interpretation and confidence -radiation exposure

-limited availability depending on region -expert reader needed

-non-specific in later stages of disease, and less sensitive in earlier stages of disease

-lower sensitivity compared to FDG-PET -cost

-radiation exposure

-insufficient clinical data for current use in clinical practice

-not readily available in all geographies -cost

-radiation exposure

-not readily available in all geographies -cost

-expert reader training required

-radiation exposure

-very limited clinical data for current use -radiation exposure

-limited availability

-expert reader training required -cost

-full alignment of standardized statistical mapping and visual rating scales not obtained at this time -atrophy may not be strongly evident in asymptomatic phase of AD

-manual measurements require experience to quantify / analyze -not specific to AD pathology

-no standardized analysis procedures and outcome measures

-data analysis is complex and requires specialized expertise

-changes over the course of asymptomatic, prodromal, and dementia stages of AD remain unclear -not specific to AD pathology 


\begin{tabular}{|c|c|c|}
\hline \multicolumn{3}{|l|}{ CSF } \\
\hline $\begin{array}{l}\text { CSF biomarkers (aß, tau) } \\
\text { (Blennow et al., Alzheimers Dement 2015; } \\
\text { Berenguer et al., Alzheimer Dis Assoc } \\
\text { Disord,2014) }\end{array}$ & $\begin{array}{l}\text {-readily available } \\
\text {-aß/tau ratio high sensitivity and } \\
\text { specificity for AD }\end{array}$ & $\begin{array}{l}\text {-collection invasive } \\
\text {-lab to lab variability } \\
\text {-full alignment of standardization of } \\
\text { technique for CSF collection not obtained } \\
\text {-no standardization of assay }\end{array}$ \\
\hline \multicolumn{3}{|l|}{ Blood and Urine } \\
\hline $\begin{array}{l}\text { TOMM40 } \\
\text { (Roses et al., Parmacogenomics J. 2010; } \\
\text { Roses et al., Alzheimers Dement 2013) }\end{array}$ & $\begin{array}{l}\text {-test is readily available } \\
\text {-minimally or non-invasive }\end{array}$ & $\begin{array}{l}\text {-uncertainty within the field on strength } \\
\text { of independent signal from APOE4 }\end{array}$ \\
\hline $\begin{array}{l}\text { PSEN1/ PSEN2 / APP } \\
\text { (Morris et al., Clinical Investig 2012) }\end{array}$ & -test is readily available & $\begin{array}{l}\text {-implications to family members } \\
\text {-not generalizable to sporadic AD } \\
\text { population }\end{array}$ \\
\hline \multicolumn{3}{|l|}{ Clinical } \\
\hline \multicolumn{3}{|l|}{ Other } \\
\hline $\begin{array}{l}\text { Ocular Measures: } \\
\text { - Eye Tracking measures to novel visual } \\
\text { stimuli } \\
\text { - Ocular (retinal or lens) Amyloid Assess- } \\
\text { ments } \\
\text { - Retinal Nerve Fiber Layer measurement } \\
\text { and vascular changes } \\
\text { (Tian et al., Dis Markers 2014; Koro- } \\
\text { nyo-Hamaoui et al., Neuroimage 2011; } \\
\text { Berisha et al., Invest Ophthalmol Vis Sci } \\
\text { 2007; Paquet et al., Neurosci Lett 2007) }\end{array}$ & $\begin{array}{l}\text {-quick } \\
\text {-readily available } \\
\text {-noninvasive } \\
\text {-inexpensive }\end{array}$ & -limited clinical data \\
\hline $\begin{array}{l}\text { EEG } \\
\text { (Buscema et al., Curr Alzheimer Res 2010) }\end{array}$ & $\begin{array}{l}\text {-noninvasive } \\
\text {-inexpensive } \\
\text {-widely available }\end{array}$ & -limited success to date \\
\hline $\begin{array}{l}\text { Magnetoencephalography } \\
\text { (Fernandez et al., J Alzheimers Dis 2013) }\end{array}$ & -noninvasive & -limited clinical data \\
\hline
\end{tabular}

Abbreviations: $\mathrm{AD}=$ Alzheimer's disease; $\mathrm{APOE}$ = apolipoprotein E; $\mathrm{CSF}=$ cerebrospinal fluid; EEG = electroencephalogram; FDA = US Food and Drug Administration; FDG = fluorodeoxyglucose; FTD = frontotemporal dementia; MRI = magnetic resonance imaging; $\mathrm{PET}=$ positron emission tomography; $\mathrm{PSEN}=$ presenilin; TOMM40 = translocase of outer mitochondrial membrane 40 homolog 
included focus on a high-risk cohort and evidence that new antiviral treatments improved outcomes among individuals at high risk for infection. Thus, the ability to select a high-risk cohort and the availability of a treatment that improves outcomes in the ADPa population, may aid in obtaining reimbursement for screening.

Unless physicians have clear incentives to screen for $\mathrm{AD}$ pathology prior to the onset of cognitive decline, reaching the ADPa patient group will be a challenge. Tests that are appropriate to screen for cognitive impairment among those with symptoms will likely differ from those needed in the ADPa population. To be useful in individuals without symptoms, a test will need to be sensitive to early cognitive changes (e.g. episodic memory) and alternative types of cognitive screening may need to be available through non-medical sources (e.g. online testing) for treatment of ADPa to become a reality.

Other factors will also influence the ability to reach the target group. In a previous study examining barriers to access, patients reported that factors such as cost of treatment, transportation, fear of diagnostic testing procedures, lack of a primary care physicians, and perceived unresponsiveness of medical professionals, contribute to the inability to reach patients (31). It will be important to consider these general factors and how they will apply to the ADPa population. The fear currently associated with receiving a diagnosis of $\mathrm{AD}$ dementia will still exist for certain individuals even in the face of an effective treatment, restricting the asymptomatic $\mathrm{AD}$ population to only those who desire to be screened. However, similar to previous experience with symptomatic $\mathrm{AD}$, the desire to make financial and care choice decisions prior to cognitive decline, may be sufficiently motivating to offset these concerns for some individuals.

The potential for insurance or employment discrimination in the ADPa population is possible, especially in the United States $(9,32,33)$. Legislation protecting individuals with a predisposition to $\mathrm{AD}$ dementia would be advisable if screening becomes commonplace, similar to protection provided by the Genetic Information Nondiscrimination Act (GINA) in the United States for genetic data, although GINA does not protect against all forms of insurance and employment discrimination. Further understanding of the medical predictors of cognitive decline and the specific behavioral challenges to overcome in the ADPa population will become clearer as research progresses.

\section{Feasibility}

Is today's health care system equipped to treat the ADPa population with an AD disease-modifying drug? What changes could better support for this future state?
In the United States alone, greater than 47 million individuals are 65 or older (34). Identifying which of these individuals are ADPa would require screening a considerable percentage of this population that has not already shown cognitive decline. The two hallmark pathologies of $\mathrm{AD}$ include cerebral neuritic plaques (amyloid) and neurofibrillary tangles (tau) (35). Currently, the two most common clinical methods of determining whether AD pathology is present are lumbar puncture (LP) and amyloid PET scans. Although readily available and relatively inexpensive, LPs are invasive and have significant lab-to-lab variability. There are ongoing efforts to develop a standard CSF assay with reduced variability. Amyloid PET imaging is highly specific for cerebral brain amyloid, however, it is expensive and not readily available globally. The quantitative measure for amyloid PET scans is the standard uptake value ratio (SUVr), but standard cut-off values and reference ranges are needed and there is uncertainty whether the cut-off values are the same across all stages of AD. PET imaging of tau is currently only used in the research setting and is not yet clinically available. Further assay standardization, tracer production and increased scanner availability will likely be required if today's most commonly used tools are to become routine for the ADPa population.

At this time, we believe that diagnostic tests (beyond amyloid PET or CSF) and risk factors with the strongest bodies of evidence to predict AD pathology and, therefore, cognitive decline, are APOE4 carrier status, age, and worsening cognition on serial cognitive assessments. It is also possible that in the near future, less expensive and readily available tests that can measure $\mathrm{AD}$ pathology in blood, urine, or retina may emerge. A future algorithm for identification of ADPa individuals may include the use of a combination of these or other measures prior to more expensive or invasive diagnostic tests. However, in order to establish the clinical utility of a potential algorithm, longitudinal studies of sufficient duration are critical to better quantify the impact of these biomarkers on cognitive trajectories.

Reimbursement for useful diagnostic tests will be a key component of any method to feasibly define the ADPa population and has been a struggle for the field, even in the symptomatic population. Amyloid PET scan reimbursement exemplifies this struggle. In the US, The Centers for Medicare and Medicaid Services (CMS) has determined that they will reimburse one scan per patient for approved studies through Coverage with Evidence Development (CED) (36). As of July, 2015, there were three approved CED studies for amyloid PET (37). Results from CED studies, together with other relevant data on the use of amyloid PET, can form the basis of a request for CMS to reconsider coverage of amyloid PET such that it would be able to be reimbursed without the requirement of being used as part of an approved CED study. However, the current CEDs do not include the 
ADPa population and require that referring physicians be dementia specialists. This is in contrast to a clinical practice environment where the ADPa individual will likely be initially seen by their primary care physician. The availability of new AD treatments that improve cognitive/clinical outcomes compared to the current standard of care may further bolster the case for the diagnostic value of amyloid PET, particularly if proof of amyloid pathology is a requirement for entry into the studies leading to approval of such drugs. Nevertheless, the ongoing clinical trials are still relatively early in their course, so many of these deciding factors will not be apparent for several years.

Once the ADPa group can be diagnostically defined, resolution of the debate as to whether such individuals should be given a diagnosis of Preclinical AD or whether they should be informed of an elevated risk for development of AD dementia is critical for broader implementation. However, support for addressing this dilemma has been mixed to date. Some studies suggest that a diagnosis of early-stage dementia causes more harm than good, resulting in unnecessary financial and clinical burdens $(38,39)$. Others report that receipt of an accurate diagnosis or disclosure of genetic status had a positive impact on most patients experiencing symptoms and their caregivers, as well as increasing the likelihood of adopting potential AD risk-reducing behaviors (40, 41). If conveying a potential diagnosis for $\mathrm{AD}$ dementia is preferred, then a more precise understanding of the incremental risks to the development of $\mathrm{AD}$ dementia should be communicated. While research into the disclosure of elevated amyloid $(42,43)$ and genetic risk $(33,41)$ has been conducted, more data on the individual predictive nature of the biomarkers is needed to understand the key messages to be conveyed to the ADPa patients, especially since it is not yet known which individuals will develop symptomatic AD.

Increased methods and capacity for identification of ADPa individuals, training for health care professionals, resolution on how to convey the results of ADP testing to patients, and support of prevention from payers, will be required for the field to move forward. Lessons can be learned from disclosures of results in other disease states, including cancer risk (44). Ongoing supportive research in asymptomatic populations such as the API APOE4 Study, and the Study of Knowledge and Reactions to Amyloid Testing (SOKRATES) will investigate the impact of APOE status and amyloid status, respectively (45) and can help inform the appropriate messages and methods for disclosure in AD. However, the advent of an inexpensive, non-invasive and widely available tool or algorithm of tools to screen the elderly population for ADPa status, and thus eligibility for a disease-modifying treatment, may prove to be the greatest facilitators of change. The quality of the ongoing trials will be robust, but the breadth will be limited by the stated 2025 timeframe for government agencies and private payers to make a decision regarding the future of diagnoses and treatments of AD.

\section{Sustainability}

\section{If we are successful in treating $A D P a$ individuals with a disease modifier, how does the health care system foster compliance and define success?}

The goals of earlier diagnosis and intervention leading to disease modification are likely to require long-term treatment. Persistence with medications varies greatly based upon a number of factors including route of administration, frequency, out-of-pocket costs, and side effect profile (46). Persistence with medications for asymptomatic conditions can be particularly challenging given the lack of feedback in the form of symptomatic relief, especially if there is no suitable biomarker to indicate whether the medication is having an effect. Estimates of adherence and persistence with medications in other asymptomatic conditions may provide useful initial estimates for the ADPa population. For example, adherence to medications for high cholesterol and for osteoporosis was $61 \%$ and $60 \%$, respectively, at one year (47). However, the adherence measure does not provide the full picture of compliance. A different study of female osteoporosis patients reported that the mean medication possession ratio was around $60 \%$ over the 60 -month follow-up period with the upper quartile consistently around $90 \%$ and the lower quartile consistently around $30 \%$ (48). Among individuals who take statins, those who only have biomarker evidence of a disease (e.g. high cholesterol) are likely to be better proxies for the ADPa population than those who take statins and have evidence of coronary heart disease. Ellis and colleagues (2004) reported that those with evidence of heart disease were less likely to discontinue their statin than those who did not have evidence of coronary heart disease (49). Similarly, individuals who take osteoporosis medications who only have evidence of low bone mineral density, but have not experienced a facture, are also likely to be a better analogue for ADPa.

It will likely require educated, motivated, health care consumers and comprehensive patient engagement programs to sustain adherence with the potential treatment regimens approved to modify $\mathrm{AD}$ pathology in asymptomatic individuals. Education will be a key factor for patients, family members, and physicians, not only for compliance to medication, but also for accurate diagnosis. Medically accepted algorithms for how and when to screen, when to treat those who have asymptomatic AD pathology and when to rescreen individuals who are negative for $\mathrm{AD}$ pathology will need to be established and widely disseminated. However, this paradigm shift required to treat ADPa patients with a disease-modifying agent is likely to take time if historical precedent for 
incorporation of research findings into clinical practice holds (50).

Health systems will need to develop treatment guidelines to help decide the appropriate use of treatments for asymptomatic AD. Payers will need evidence of the benefits of screening and treatment of $\mathrm{ADPa}$ on patient outcomes in order to make coverage determinations. They will also likely seek to determine the sub-populations that are most likely to respond well to treatment as well as also those who are likely to progress to mild cognitive impairment $(\mathrm{MCI})$ and $\mathrm{AD}$ dementia. Payers that have responsibility for all aspects of care of an individual, regardless of age, are better positioned to take a longer term perspective that better aligns the value of investment in earlier treatment, given that most benefits of delayed progression will not be realized until years later.

\section{Transferability}

If treatment is successfully initiated prior to onset of cognitive symptoms, how will this inform treatment in the symptomatic phases of illness? How can other disease states inform the shift to incorporate treatment of an asymptomatic condition?

When a disease-modifying agent is available to treat $\mathrm{ADPa}$, biomarker testing for AD pathology will likely be a requirement for diagnosis and will need to become part of routine screening practice in the primary care setting. Regional considerations such as availability of the necessary diagnostic tools, criteria for approval of novel therapies, and physician education will drive unique usage patterns across the globe. However, as effective disease-modifying agents are adopted into clinical practice, the progression to symptomatic stages will be delayed, resulting in a lower incidence of symptomatic AD. As a result, the role of dementia specialists may shift and they will be routinely sought to help diagnose symptomatic stages of $\mathrm{AD}$ for those not detected prior to symptom onset, to initiate symptomatic therapy, and for treatment of psychiatric and behavioral symptoms of AD dementia. Specialists may also play a role in staging illness to determine discontinuation and changing of treatments, especially if specific medications are not indicated for symptomatic phases of illness. Specialists will also likely be increasingly asked to evaluate patients who are cognitively symptomatic, but do not have evidence of AD pathology, such as suspected non-AD pathology (51).

The concept of transferability can also be expanded to consider lessons learned in other disease states. For example, while the treatment of cardiovascular disease (CVD) is still a major part of medical care, prevention of CVD events, such as myocardial infarctions, have been a focus of research and clinical practice for decades. However, prevention of the disease was not believed possible in the 1950s when clinical trials with therapeutic interventions became more prevalent (52). Over time, clinical trials were expanded to investigate both population-level data and the translation into individual risk prediction models to support early identification of individuals with the condition, similar to the current state of AD studies. Cardiovascular disease is usually diagnosed only after a review of risk factors and multiple tests including electrocardiograms, stress tests, echocardiograms, blood biomarkers and coronary angiography. However, the current American College of Cardiology/American Heart Association Task treatment guidelines include, but do not require, a diagnosis of CVD prior to initiation of statin therapy.

While there are parallels between the prevention of cardiovascular disease to treatment of ADPa, this comparison also highlights gaps in the available tools and data to make this transition within $\mathrm{AD}$ management. A notable difference between the two disease states includes a routine biomarker test showing the efficacy of treatment in lowering a surrogate biomarker endpoint. Cholesterol testing is an inexpensive, minimally invasive biomarker through which the reduction in plaque-causing elements can be measured to show the effectiveness of treatment. At this time, the significance of reducing $\mathrm{AD}$ pathology in the brain versus the periphery is not fully known, nor is it known to what degree $\mathrm{AD}$ pathology must be reduced to achieve a clinical benefit. If a surrogate marker for modification of disease pathology is not available, evaluation of therapeutic efficacy and compliance in an ADPa population will have even greater hurdles. An AD risk algorithm, similar to the Framingham risk score for coronary heart disease, would be beneficial in both research and clinical practice. The Framingham heart study has collected detailed longitudinal information since its inception in 1948 and, while desirable, the $\mathrm{AD}$ community is unlikely to have that level of data available prior to a disease-modifying intervention entering the market.

Careful benefit versus risk assessment is essential for any new medication and was carefully assessed at the time of the approval of the statins. However, recent experience has shown that the hurdles necessary to achieve the paradigm shift in $\mathrm{AD}$ are growing and more difficult to surmount than in past decades. A significant question that needs to be addressed is whether the data available by 2025 will be sufficient to meet this high bar for the ADPa population to benefit from therapy. Data on the trajectory from ADPa through other stages of $\mathrm{AD}$ will be key in modeling the longer-term impact of interventions. Since initial clinical trial data will be over a shorter time frame, it is not likely to encompass much symptomatic, let alone, functional decline. Although there are numerous longitudinal databases that contain data of relevance to the ADPa population (53), more comprehensive data sources are needed to adequately 
characterize this population, and establishing appropriate estimates of the disease trajectory will be challenging (54).

There are also hurdles in coverage that need to be addressed. As noted previously, biomarker diagnostics will be essential to identify ADPa individuals who are appropriate candidates for disease-modifying interventions. However, a recent study reported that CMS coverage of medical interventions (including diagnostics) in national coverage determinations has become increasingly more restrictive over the past 15 years (55). Payment for prevention is particularly problematic, with costs spread over a longer period than payers may find acceptable and with difficulty in measuring the effects of an intervention on meaningful endpoints. While the measurement challenge is universal, demonstrating the benefit of paying for prevention may be easier in countries where one government entity pays for care at all ages. Although payment for healthcare is more fragmented in the US, innovative approaches to pay for prevention are being evaluated. CMS recently announced a plan to pay for reductions in long-term hard outcomes by a surrogate endpoint of predicted risk through the Million Hearts Cardiovascular Risk Reduction Model (56). If this approach is successful, it could be applied to other preventive care, including use in ADPa individuals. While methods to support overall health in aging should continue, research consortia and collaborations will be needed to extend the results of the ongoing clinical trials beyond the research stage.

\section{Discussion}

The shift to focus research efforts in the asymptomatic AD population has developed momentum; however, even if ongoing and future trials in the ADPa population are successful, many obstacles will need to be addressed to successfully bring an approved treatment to the target population. As outlined, some of these obstacles include the need for alignment on terminology, defining clinical and societal meaningfulness in this population, changing clinical practice, establishing and standardizing diagnostic tools and algorithms with improved accessibility, as well as increased education and acceptance by regulators, payers and healthcare systems.

Using an existing public health framework (11) with five impact elements (effectiveness, reach, feasibility, sustainability and transferability (Table 2)), has limitations for examination of the practice of using disease-modifying agents in the ADPa population. Knowledge of specific approved treatments is required to fully assess the impact of a practice. Since no diseasemodifying agents are yet approved, no data exists to assess the "quality of evidence" aspect of the framework, and thus was not examined here.

An additional limitation is that although numerous longitudinal studies in the ADPa population are ongoing, the current lack of epidemiological data greatly contributes to the uncertainties in translation to clinical practice. Much of the available data examining trends of disease progression are from observational or longitudinal studies which were designed for other purposes and do not fully model the trajectory of decline from asymptomatic to symptomatic stages, with and without AD pathology. Absent a greater understanding the trajectory of decline and an understanding of normal aging, assessing the impact of treatment becomes even more challenging.

The paradigm shift in the conceptualization, diagnosis and treatment of $\mathrm{AD}$ will be substantial. However, the lag time between research findings and clinical implementation may be considerable (15). If regulators, payers and health care professionals are not sufficiently aware of the potential impacts of this ongoing research, delays in reaching the asymptomatic AD population will be widespread. Discussions between regulators, payers, academic experts, health systems and the pharmaceutical industry should begin now to anticipate this potential future need and avoid significant delays translating research results into clinical practice. If the hypothesis that "earlier is better" proves to be true, these delays can meaningfully impact those on the tipping point of decline, perhaps in ways that cannot be recovered. Additionally, further research complementary to ongoing drug trials should be initiated to achieve the global 2025 goals.

We can look to other disease states that have gone through obstacles similar to the ones currently facing the $\mathrm{AD}$ field as a model to help guide us over the next few critical years. For example, in cardiovascular disease, governmental agencies played a key role in funding the longitudinal epidemiology studies to inform and place the results of all future research into a useable clinical context. Additional information regarding the trajectory of cognitive decline from asymptomatic to symptomatic stages of $\mathrm{AD}$ will be necessary to address key questions on value of early treatment. We echo the call from Rosenberg and Petersen (57) that government support of these initiatives is the key to success. Further, legislations to protect those who have pathology consistent with $\mathrm{AD}$ dementia should be drafted and introduced, not only for medical insurance, but also for long-term disability, life insurance, and workplace discrimination.

We have attempted to highlight existing and potential barriers to enable discussion of potential solutions to help mitigate the growing global heath impact of dementia due to $\mathrm{AD}$. The most compelling reasons to act, the approval of a disease-modifying agent or a successful clinical trial in asymptomatic $\mathrm{AD}$ patients, have yet to become reality. If we start to address these gaps now, the global goal of preventing or delaying the onset of dementia due to AD by 2025 is more likely to become a reality.

Acknowledgments: The authors thank Drs. Adam S. Fleisher, Kristin KahleWrobleski, Adam J. Schwarz, and Robert Dean for their scientific expertise 
and critical revisions. All authors have contributed to the conception and interpretation of the manuscript, have either drafted or critically revised the content, and have approved the final version of the manuscript.

Funding: Funding for this project was provided by Eli Lilly and Company (Indianapolis, Indiana, USA).

Conflicts of interest: Drs. Downing, Yaari, Ball, and Selzler are employees and minor shareowners of Eli Lilly and Company. Dr. Devous is an employee of Avid Radiopharmaceuticals, a wholly owned subsidiary of Eli Lilly.

\section{References}

1. Doody RS, Thomas RG, Farlow M et al. Phase 3 trials of solanezumab for mild-to-moderate Alzheimer's disease. N Engl J Med 2014;370(4):311-321.

2. Cummings, J, Cho W, Ward M, et al. [Abstract] A Randomized, doubleblind, placebo-controlled Phase 2 study to evaluate the efficacy and safety of crenezumab in patients with mild to moderate Alzheimer's disease. Alzheimer's Association International Conference 2014. http://www. alzheimersanddementia.com/article/S1552-5260(14)00578-0/pdf

3. Dubois B, Feldman HH, Jacova C, et al. Research criteria for the diagnosis of Alzheimer's disease: revising the NINCDS-ADRDA criteria. Lancet Neurol 2007;6:734-746.

4. Dubois B, Feldman HH, Jacova C, et al. Revising the definition of Alzheimer's disease: a new lexicon. Lancet Neurol 2010;9(11):1118-1127.

5. Sperling RA, Aisen PS, Beckett LA, et al. Toward defining the preclinica stages of Alzheimer's disease: recommendations from the National Institute on Aging-Alzheimer's Association workgroups on diagnostic guidelines for Alzheimer's disease. Alzheimers Dement 2011;7(3):280-292.

6. Fleisher AS, Chen K, Liu X, et al. Apolipoprotein E $\varepsilon 4$ and age effects on florbetapir positron emission tomography in healthy aging and Alzheimer disease. Neurobiol Aging 2013;34(1):1-12

7. Rodrigue KM, Kennedy KM, Park DC. Beta-amyloid deposition and the aging brain. Neuropsychol Rev 2009;19(4):436-450.

8. Fougère B, Vellas B, Delrieu J et al. The Road Ahead To Cure And Prevent Alzheimer's Disease: Implementing Prevention into Primary Care. J Prev Alzheimers Dis 2015; in press.

9. Karlawish J. How are we going to live with Alzheimer's disease? Health Aff (Millwood) 2014;33(4):541-546.

10. Sperling RA, Karlawish J, Johnson KA. Preclinical Alzheimer disease-the challenges ahead. Nat Rev Neurol 2013;9(1):54-58.

11. Spencer LM, Schooley MW, Anderson LA, et al. Seeking best practices: a conceptual framework for planning and improving evidence-based practices. Prev Chronic Dis 2013;10:E207.

12. National Dementia Plans. Alzheimer Europe. 2015. http://www.alzheimereurope.org/Policy-in-Practice2/National-Dementia-Plans. Accessed 8 July 2015

13. National Plan to Address Alzheimer's Disease 2014 Update. U.S. Department of Health and Human Services. 2014. http://aspe.hhs.gov/daltcp/napa/ NatlPlan2014.shtml. Accessed 8 July 2015

14. G8 Dementia Summit, Global Action Against Dementia. 2013. https:// www.gov.uk/government/uploads/system/uploads/attachment_data / file/265868/2901669_G8_DementiaSummitCommunique_acc.pdf. Accessed 8 June 2015.

15. Sloane PD, Zimmerman S, Suchindran C, et al. The public health impact of Alzheimer's disease, 2000-2050: potential implication of treatment advances. Annu Rev Public Health 2002;23:213-231.

16. Alzheimer's Association. 2015. Changing the trajectory of Alzheimer's disease: How a treatment by 2025 saves lives and dollars. http:/ / www.alz. org/documents_custom/trajectory.pdf. Accessed 8 June 2015 and 8 July 2015.

17. Wimo A, Jonsson L, Bond J, Prince M, Winblad B; Alzheimer Disease International. The worldwide economic impact of dementia 2010. Alzheimers Dement 2013;9(1):1-11 e13.

18. Oremus M, Aguilar SC. A systematic review to assess the policy-making relevance of dementia cost-of-illness studies in the US and Canada. Pharmacoeconomics 2011;29(2):141-156.

19. Dementia fact sheet: Rates of dementia. World Health Organization. 2015. http:// www.who.int/mediacentre/factsheets/fs362/en/. Accessed 4 June 2015.

20. Zissimopoulos J, Crimmins E, St.Clair P. The Value of Delaying Alzheimer's Disease Onset, Forum for Health Economics \& Policy 2015;18(1):25-39.

21. Health secretary announces $\$ 100 \mathrm{~m}$ Dementia Discovery Fund. UK Department of Health. 2015. https://www.gov.uk/government/news/ health-secretary-announces-100m-dementia-discovery-fund. Accessed 8 June 2015.

22. Yaari R, Hake A. Alzheimer's disease clinical trials: past failures and future opportunities. Clin Invest 2015;5(3):297-309.

23. Siemers E, Sundell K, Carlson C et al. Phase 3 solanezumab trials: Secondary outcomes in mild Alzheimer's disease patients. Alzheimers Dement 2015 [in press].

24. Liu-Seifert $\mathrm{H}$, Siemers E, Price $\mathrm{K}$ et al. Cognitive impairment precedes and predicts functional impairment in mild Alzheimer's disease. J Alzheimers Dis 2015 [in press].

25. World Alzheimer Report 2011. Alzheimer's Disease International. 2011 http: / / www.alz.co.uk/ research/WorldAlzheimerReport2011Executive Summary.pdf. Accessed 1 July 2015.

26. Dementia Statistics. Alzheimer's Disease International. 2013. http://www. alz.co.uk/ research/statistics. Accessed 1 July 2015.

27. Lannfelt L, Relkin NR, Siemers ER. Amyloid-ß-directed immunotherapy for Alzheimer's disease. J Intern Med 2014;275(3):284-295.

28. Hunter CA, Kirson NY, Desai U, Cummings AKG, Faries DE, Birnbaum HG. Medical costs of Alzheimer's disease misdiagnosis among US Medicare beneficiaries Alzheimers Dement 2015; in press.

29. Cognitive impairment in older adults: March 2014. U.S. Preventive Services http://www.uspreventiveservicestaskforce.org/Page/Document / RecommendationStatementFinal/ cognitive-impairment-in-older-adultsscreening. Accessed 23 June 2015.

30. Hepatitis B, Non Pregnant Adolescents and Adults: May 2014. U.S. Preventive Services Task Force. 2014. http://www.uspreventiveservicestas kforce.org/Page/Document/RecommendationStatementFinal/ hepatitis-bvirus-infection-screening-2014. Accessed 23 June 2015.

31. Fitzpatrick AL, Powe NR, Cooper LS, Ives DG, Robbins JA. Barriers to health care access among the elderly and who perceives them. Am J Public Health 2004;94(10):1788-1794.

32. Karlawish J. Addressing the ethical, policy and social challenges of preclinical Alzheimer disease. Neurology 2011;77:1487-1493.

33. Green RC, Christensen KD, Cupples LA, et al. A randomized noninferiority trial of condensed protocols for genetic risk disclosure of Alzheimer's disease. Alzheimers Dement 2014;Dec 9: pii: S1552-5260(14)02870-2 [epub ahead of print]

34. 2014 National Population Projections. U.S. Census Bureau. 2014. https:// www.census.gov/population/projections / data/national / 2014 / summarytables.html. Accessed 1 July 2015.

35. Braak H, Braak E. Neuropathological stageing of Alzheimer-related changes. Acta Neuropathol 1991;82(4):239-259.

36. Centers for Medicare and Medicaid Services. 2013. Decision memo for beta amyloid positron emission tomography in dementia and neurogenerative disease (CAG-00431N). http:/ / www.cms.gov/medicare-coverage-database/ details / nca-decision-memo.aspx?NCAId=265. Accessed 8 June 2015.

37. Major new research study to demonstrate the value of PET scans in Alzheimer's disease diagnosis. Alzheimer's Association. 2015. http:/ www.alz.org/documents_custom/IDEAS_study_news_release_041615.pdf. Accessed 8 June 2015.

38. Le Couteur DG, Doust J, Creasey H, Brayne C. Political drive to screen for pre-dementia: not evidence based and ignores the harms of diagnosis. BMJ 2013;347:f5125

39. Moyer V. Screening for Cognitive Impairment in Older Adults: U.S. Preventive Services Task Force Recommendation Statement. Ann Intern Med 2014;160(11):791-797.

40. Carpenter BD, Xiong C, Porensky EK, et al. Reaction to a dementia diagnosis in individuals with Alzheimer's disease and mild cognitive impairment. J Am Geriatr Soc 2008;56(3):405-412.

41. Green RC, Roberts JS, Cupples LA, et al. Disclosure of APOE genotype for risk of Alzheimer's disease. N Engl J Med. 2009; 361(3):245-254.

42. Harkins K, Sankar P, Sperling R, et al. Development of a process to disclose amyloid imaging results to cognitively normal older adult research participants. Alzheimers Res Ther 2015;7(1):26.

43. Sperling RA, Rentz DM, Johnson KA, et al. The A4 study: stopping AD before symptoms begin? Sci Transl Med 2014;6(228):228fs213.

44. Patrick-Miller LJ, Egleston BL, Fetzer D, Forman A, Bealin L, et al. Development of a communication protocol for telephone disclosure of genetic test results for cancer predisposition. JMIR Res Protoc 2014;3(4):e49.

45. Alzheimer's Association International Conference 2015. Alzforum. How Do You Communicate Alzheimer's Risk in the Age of Prevention? Retrieved 2 September 2015 from http://www.alzforum.org/news/conferencecoverage/how-do-you-communicate-alzheimers-risk-age-prevention.

46. Osterberg L, Blaschke T. Adherence to Medication. New Engl J Med 2005;353(5):487-497.

47. Yeaw J, Benner JS, Walt JG, Sian S, Smith DB. Comparing adherence and persistence across 6 chronic medication classes. J Manag Care Pharm 2009;15(9):728-740.

48. Huybrechts KF, Ishak KJ, Caro JJ. Assessment of compliance with osteoporosis treatment and its consequences in a managed care population. Bone 2006;38(6):922-928.

49. Ellis J, Erickson S, Stevenson J, Bernstein S, Stiles R, Fendrick A. Suboptimal statin adherence and discontinuation in primary and secondary prevention populations. J Gen Intern Med. 2004;19(6):638-645.

50. Green L, Seifert C. Translation of Research Into Practice: Why We Can't "Just Do It". J Am Board Fam Pract 2005;18(6):541-545.

51. Jack CR, Jr. PART and SNAP. Acta Neuropathol 2014;128(6):773-776. 1

2. Yusuf S. Two decades of progress in preventing vascular disease. Lancet 
2002;360(9326):2-3.

53. Bell JF, Fitzpatrick AL, Copeland C, et al. Existing data sets to support studies of dementia or significant cognitive impairment and comorbid chronic conditions. Alzheimers Dement 2015;11(6):622-638.

54. Erten-Lyons D, Sherbakov LO, Piccinin AM, et al. Review of selected databases of longitudinal aging studies. Alzheimers Dement 2012;8(6):584589.

55. Chambers JD, Chenoweth M, Cangelosi MJ, Pyo J, Cohen JT, Neumann PJ. Medicare is scrutinizing evidence more tightly for national coverage determinations. Health Aff (Millwood) 2015;34(2):253-260.

56. Sanghavi DM, Conway PH. Paying for Prevention: A Novel Test of Medicare Value-Based Payment for Cardiovascular Risk Reduction. JAMA 2015;314(2):123-124.

57. Rosenberg RN, Petersen RC. The Human Alzheimer Disease Project: A new call to arms. JAMA Neurol 2015;72(6):626-628.

\section{References for Table 2}

- Biomarker Qualification for Risk of Mild Cognitive Impairment (MCI) Due to Alzheimer's Disease (AD) and Safety and Efficacy Evaluation of Pioglitazone in Delaying Its Onset (TOMMORROW). 2015. https: / / clinicaltrials.gov/ct2/ show / NCT01931566. Accessed 14 July 2015.

- Clinical Trial of Solanezumab for Older Individuals Who May be at Risk for Memory Loss (A4). 2015. https:/ / clinicaltrials.gov/ct2/ show/NCT02008357. Accessed 14 July 2015.

- Davies, Sperling Share 2015 Potamkin Prize. 2015. http://www.alzforum. org/news / community-news / davies-sperling-share-2015-potamkin-prize. Accessed 8 July 2015.

- Dominantly Inherited Alzheimer Network Trial: An Opportunity to Prevent Dementia. A Study of Potential Disease Modifying Treatments in Individuals at Risk for or With a Type of Early Onset Alzheimer's Disease Caused by a Genetic Mutation. (DIAN-TU). 2015. https: / / www.clinicaltrials.gov/ct2 / show/NCT01760005. Accessed 14 July 2015.

- Donohue MC, Sperling RA, Salmon DP, et al. The preclinical Alzheimer cognitive composite: measuring amyloid-related decline. JAMA neurology. 2014;71(8):961-970.

- Morris JC, Aisen PS, Bateman RJ, et al. Developing an international network for Alzheimer research: The Dominantly Inherited Alzheimer Network. Clinical investigation. 2012;2(10):975-984.

- $\quad$ Novartis to Partner with Banner Health on ApoE4 Prevention Trial. 2014. http: / / www.alzforum.org/news/ conference-coverage/ novartis-partnerbanner-health-apoe4-prevention-trial. Accessed 8 June 2015.

- Reiman EM, Langbaum JB, Fleisher AS, et al. Alzheimer's Prevention Initiative: a plan to accelerate the evaluation of presymptomatic treatments Journal of Alzheimer's disease. 2011;26 Suppl 3:321-329.

- Reiman EM, Tariot PN, Langbaum JB, et al. The Collaboration for Alzheimer's Prevention (CAP): Advancing the evaluation of Alzheimer's preclinical treatments together. Nature Reviews Neurol. 2015 [in press].

- Rodriguez-Gomez O, Palacio-Lacambra ME, Palasi A, Ruiz-Laza A, BoadaRovira M. Prevention of Alzheimer's disease: a global challenge for next generation neuroscientists. Journal of Alzheimer's disease. 2014;42 Supp 4:S515-523.

- $\quad$ Roses AD, Lutz MW, Crenshaw DG, Grossman I, Saunders AM, Gottschalk WK. TOMM40 and APOE: Requirements for replication studies of association with age of disease onset and enrichment of a clinical trial. Alzheimer's \& Dementia. 2013;9(2):132-136.

- $\quad$ Sperling R, Mormino E, Johnson K. The evolution of preclinical Alzheimer's disease: implications for prevention trials. Neuron. 2014;84(3):608-622.

- $\quad$ Sperling RA, Rentz DM, Johnson KA, et al. The A4 study: stopping AD before symptoms begin? Science translational medicine. 2014;6(228):228fs213.

\section{References for Table 3}

- Berenguer RG, Monge Argiles JA, Ruiz CM, Payá JS, Blanco Cantó MA, Santana CL. Alzheimer disease cerebrospinal fluid biomarkers predict cognitive decline in healthy elderly over 2 years. Alzheimer Dis Assoc Disord 2014;28(3):234-238.

- Berisha F, Feke GT, Trempe CL, McMeel JW, Schepens CL. Retinal abnormalities in early Alzheimer's disease. Invest Ophthalmol Vis Sci 2007;48(5):2285-2289.

- Blennow K, Dubois B, Fagan AM, Lewczuk P, de Leon MJ, Hampel H. Clinical utility of cerebrospinal fluid biomarkers in the diagnosis of early Alzheimer's disease. Alzheimers Dement 2015;11(1):58-69.

- $\quad$ Bohnen NI, Djang DS, Herholz K, Anzai Y, Minoshima S. Effectiveness and safety of 18F-FDG PET in the evaluation of dementia: a review of the recent literature. J Nucl Med 2012;53(1):59-71.
- $\quad$ Braak H, Braak E. Neuropathological stageing of Alzheimer-related changes. Acta neuropathologica. 1991;82(4):239-259.

- $\quad$ Buscema M, Grossi E, Capriotti M, Babiloni C, Rossini P. The I.F.A.S.T. model allows the prediction of conversion to Alzheimer disease in patients with mild cognitive impairment with high degree of accuracy. Curr Alzheimer Res 2010;7(2):173-187.

- $\quad$ Chien DT, Bahri S, Szardenings AK, et al. Early clinical PET imaging results with the novel PHF-tau radioligand [F-18]-T807. J Alzheimers Dis 2013;34(2):457-468.

- $\quad$ Cohen AD, Klunk WE. Early detection of Alzheimer's disease using PiB and FDG PET. Neurobiol Dis 2014;72 Pt A:117-122.

- Darby DG, Brodtmann A, Pietrzak RH, et al. Episodic memory decline predicts cortical amyloid status in community-dwelling older adults. J Alzheimers Dis 2011;27(3):627-637.

- $\quad$ Farrer LA, Cupples LA, Haines JL, et al. Effects of age, sex, and ethnicity on the association between apolipoprotein E genotype and Alzheimer disease. A meta-analysis. APOE and Alzheimer Disease Meta Analysis Consortium. JAMA 1997;278(16):1349-1356.

- Fernandez A, Turrero A, Zuluaga P, et al. MEG delta mapping along the healthy aging-Alzheimer's disease continuum: diagnostic implications. J Alzheimers Dis 2013;35(3):495-507.

- Gietl AF, Warnock G, Riese F, et al. Regional cerebral blood flow estimated by early $\mathrm{PiB}$ uptake is reduced in mild cognitive impairment and associated with age in an amyloid-dependent manner. Neurobiol Aging 2015;36(4):16191628 .

- $\quad$ Gordon BA, Zacks JM, Blazey T, et al. Task-evoked fMRI changes in attention networks are associated with preclinical Alzheimer's disease biomarkers. Neurobiol Aging 2015;36(5):1771-1779.

- Jack CR, Jr. Alliance for aging research AD biomarkers work group structural MRI. Neurobiol Aging 2011;32 Suppl 1:S48-57.

- Jessen F, Amariglio RE, van Boxtel M, et al. A conceptual framework for research on subjective cognitive decline in preclinical Alzheimer's disease. Alzheimers Dement 2014;10(6):844-852.

- Koronyo-Hamaoui M, Koronyo Y, Ljubimov AV, et al. Identification of amyloid plaques in retinas from Alzheimer's patients and noninvasive in vivo optical imaging of retinal plaques in a mouse model. Neuroimage 2011;54 Suppl 1:S204-217.

- $\quad$ Laske C, Sohrabi HR, Frost SM, et al. Innovative diagnostic tools for early detection of Alzheimer's disease. Alzheimers Dement 2015;11(5):561-578.

- Madasamy S, Chaudhuri V, Kong R, et al. Plaque array method and proteomics-based identification of biomarkers from Alzheimer's disease serum. Clin Chim Acta 2015;441:79-85.

- Mapstone M, Cheema AK, Fiandaca MS, et al. Plasma phospholipids identify antecedent memory impairment in older adults. Nat Med 2014;20(4):415-418.

- Morris JC, Aisen PS, Bateman RJ, et al. Developing an international network for Alzheimer research: The Dominantly Inherited Alzheimer Network. Clinical Investig (Lond) 2012;2(10):975-984.

- Paquet C, Boissonnot M, Roger F, Dighiero P, Gil R, Hugon J. Abnormal retinal thickness in patients with mild cognitive impairment and Alzheimer's disease. Neurosci Lett 2007;420(2):97-99.

- $\quad$ Roses AD, Lutz MW, Amrine-Madsen H, et al. A TOMM40 variablelength polymorphism predicts the age of late-onset Alzheimer's disease. Pharmacogenomics J 2010;10(5):375-384

- $\quad$ Roses AD, Lutz MW, Crenshaw DG, Grossman I, Saunders AM, Gottschalk WK. TOMM40 and APOE: Requirements for replication studies of association with age of disease onset and enrichment of a clinical trial. Alzheimers Dement 2013;9(2):132-136.

- $\quad$ Rowe CC, Villemagne VL. Brain Amyloid Imaging. J Nucl Med Technol 2013;41(1):11-18.

- $\quad$ Sattlecker M, Kiddle SJ, Newhouse S, et al. Alzheimer's disease biomarker discovery using SOMAscan multiplexed protein technology. Alzheimers Dement 2014;10(6):724-734.

- $\quad$ Sperling R. Potential of functional MRI as a biomarker in early Alzheimer's disease. Neurobiol Aging. 2011;32 Suppl 1:S37-43.

- Tian T, Zhang B, Jia Y, Li Z. Promise and challenge: the lens model as a biomarker for early diagnosis of Alzheimer's disease. Dis Markers 2014;2014:826503.

- $\quad \mathrm{Tu}$ P, Fu H, Cui M. Compounds for imaging amyloid-b deposits in an Alzheimer's brain: a patent review. Expert Opin Ther Pat 2015;25(4):413-423.

- Villemagne VL, Fodero-Tavoletti MT, Masters CL, Rowe CC. Tau imaging: early progress and future directions. Lancet Neurol 2015;14(1):114-124.

- Zhang J, Zhang CH, Li RJ, et al. Accuracy of urinary AD7c-NTP for diagnosing Alzheimer's disease: a systematic review and meta-analysis. J Alzheimers Dis 2014;40(1):153-159.

- Zhang S, Han D, Tan X, Feng J, Guo Y, Ding Y. Diagnostic accuracy of 18 F-FDG and 11 C-PIB-PET for prediction of short-term conversion to Alzheimer's disease in subjects with mild cognitive impairment. Int J Clin Pract 2012;66(2):185-198. 